\title{
Simultaneous acute inflammation in entopic and ectopic pancreas
}

\author{
E W BENBOW \\ From the Department of Pathology, University of Manchester
}

SUMMARY The necropsy findings in an elderly woman, who had been treated with methyldopa and who had died during treatment for accidental hypothermia, showed acute periductal inflammation of obviously similar duration in an entopic pancreas in the wall of the jejunum and in the ectopic pancreas. This supports the hypothesis that attempted drug detoxification by pancreatic tissue can cause pancreatitis.

Acute pancreatitis is an important cause of mortality and serious morbidity, and on occasion is so fulminating in its course that it leads to sudden death.' Possible causes of acute pancreatitis can be divided into two major categories: those with local mechanisms, where the initial pancreatic damage is believed to be in the pancreatic duct; and those that are a consequence of a generalised disorder, in which ischaemia is thought to be of fundamental importance. ${ }^{2}$ The histological distribution of pancreatic damage has recently been shown to correlate well with these two groups of underlying disorders, ${ }^{34}$ and a new morphological classification has been proposed on this basis. ${ }^{3}$ This is in addition to the traditional one, which falls into categories such as oedematous, haemorrhagic, and necrotic, ${ }^{5}$ all reflecting duration or severity rather than underlying cause or any associated conditions, and into parenchymal or stromal, depending on the location of the inflammatory infiltrate.

As far as we know, this report is the first description of acute ectopic pancreatitis associated with hypothermia, and also of simultaneous acute inflammation in both an ectopic pancreas and the entopic pancreas.

\section{Case report}

An 85 year old woman was found collapsed on the floor of her home. She had been admitted several times to a geriatric hospital elsewhere, and had a current prescription for methyldopa. No other history was available. On admission she was drowsy and dehydrated, with a rectal temperature of $31.2^{\circ} \mathrm{C}$; her blood pressure was $115 / 60 \mathrm{mmHg}$. There was no apparent cyanosis. She had a normochromic anaemia,

Accepted for publication 24 November 1987 with a haemoglobin of $9.0 \mathrm{~g} / \mathrm{dl}$, and a leucocytosis of $16.0 \times 10^{9} / 1 \quad(90 \%$ neutrophil polymorphs $)$. She appeared to be in prerenal uraemia, with a serum urea concentration of $42 \cdot 1 \mathrm{mmol} / \mathrm{l}$, a creatinine concentration of $958 \mu \mathrm{mol} / \mathrm{l}$, sodium of $147 \mathrm{mmol} / \mathrm{l}$, and potassium of $4.6 \mathrm{mmol} / \mathrm{l}$. Her glucose concentration was slightly raised at $9.1 \mathrm{mmol} / \mathrm{l}$ on admission, though there was no evidence of glycosuria or ketonuria. Thyroxine activity was just below the normal limit for our laboratory at $44 \mathrm{nmol} / \mathrm{l}$. Serum amylase activity was not measured. She was rehydrated with intravenous fluids and wrapped in a space-blanket. Despite these measures she died 56 hours after admission.

\section{Pathology}

At necropsy she had plentiful mucopurulent material in the bronchi, consistent with an acute attack of chronic bronchitis; there was evidence of resolving bronchopneumonia, together with more active pneumonia of very limited extent. There was left ventricular hypertrophy of moderate degree, with histological changes in the renal vessels consistent with benign hypertension. In addition, there was a small recent renal infarct, together with focal acute pyelonephritis. The interatrial septum of the heart contained a probe-patent defect. The liver was normal, both macroscopically and microscopically, and the gall bladder and bile ducts appeared unremarkable.

A lobulated brown mass (fig 1), measuring $2 \mathrm{~cm}$ in diameter, protruded from the serosa of the jejunum at a point about $5 \mathrm{~cm}$ anterior to its emergence from the retroperitoneum. This was an ectopic pancreas, with well defined ducts and acini. Islets of Langerhans' cells were not seen, though immunohistochemical stains were not used. The interlobar ducts contained an acute 


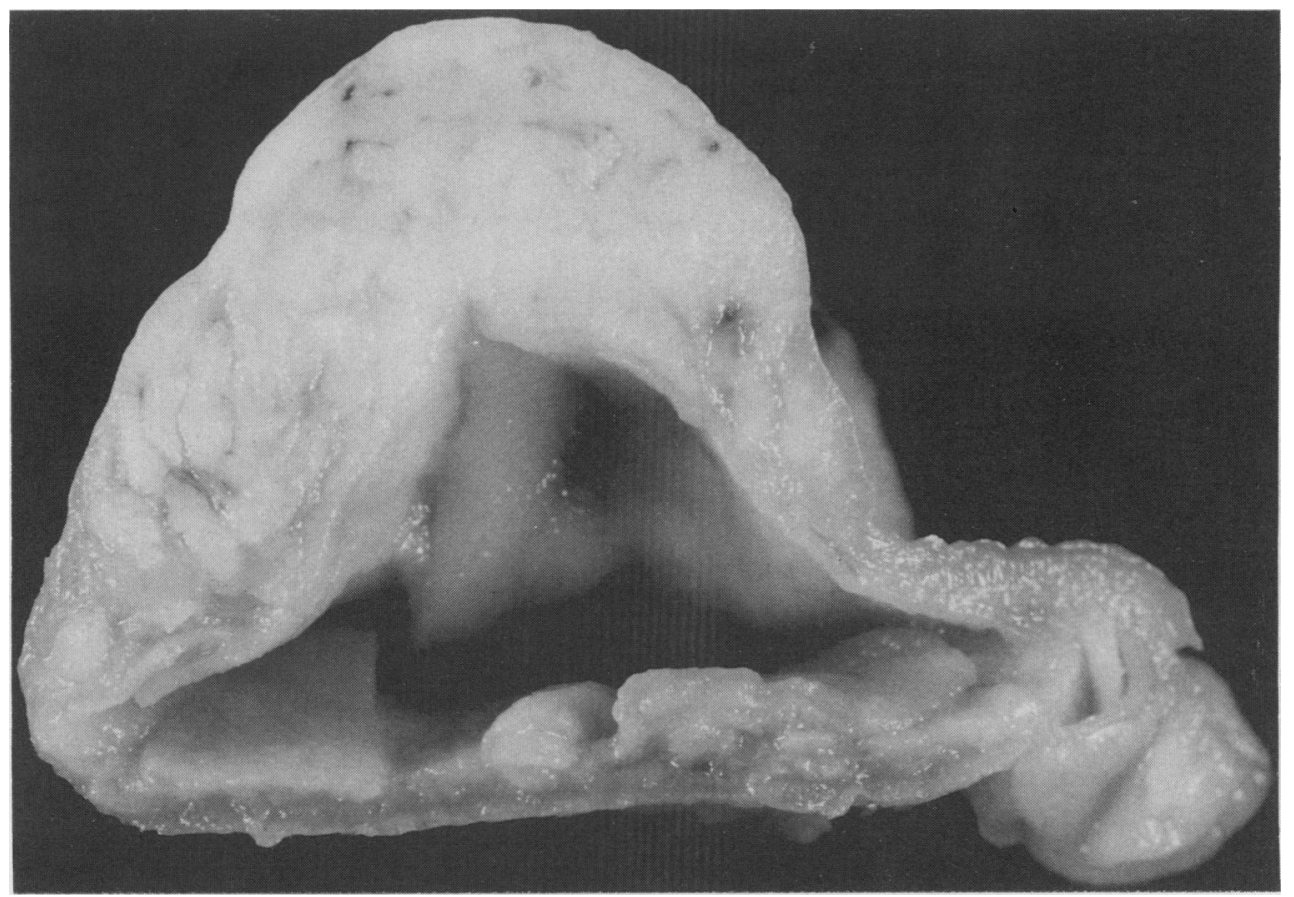

pancreatic tissue within its wall.

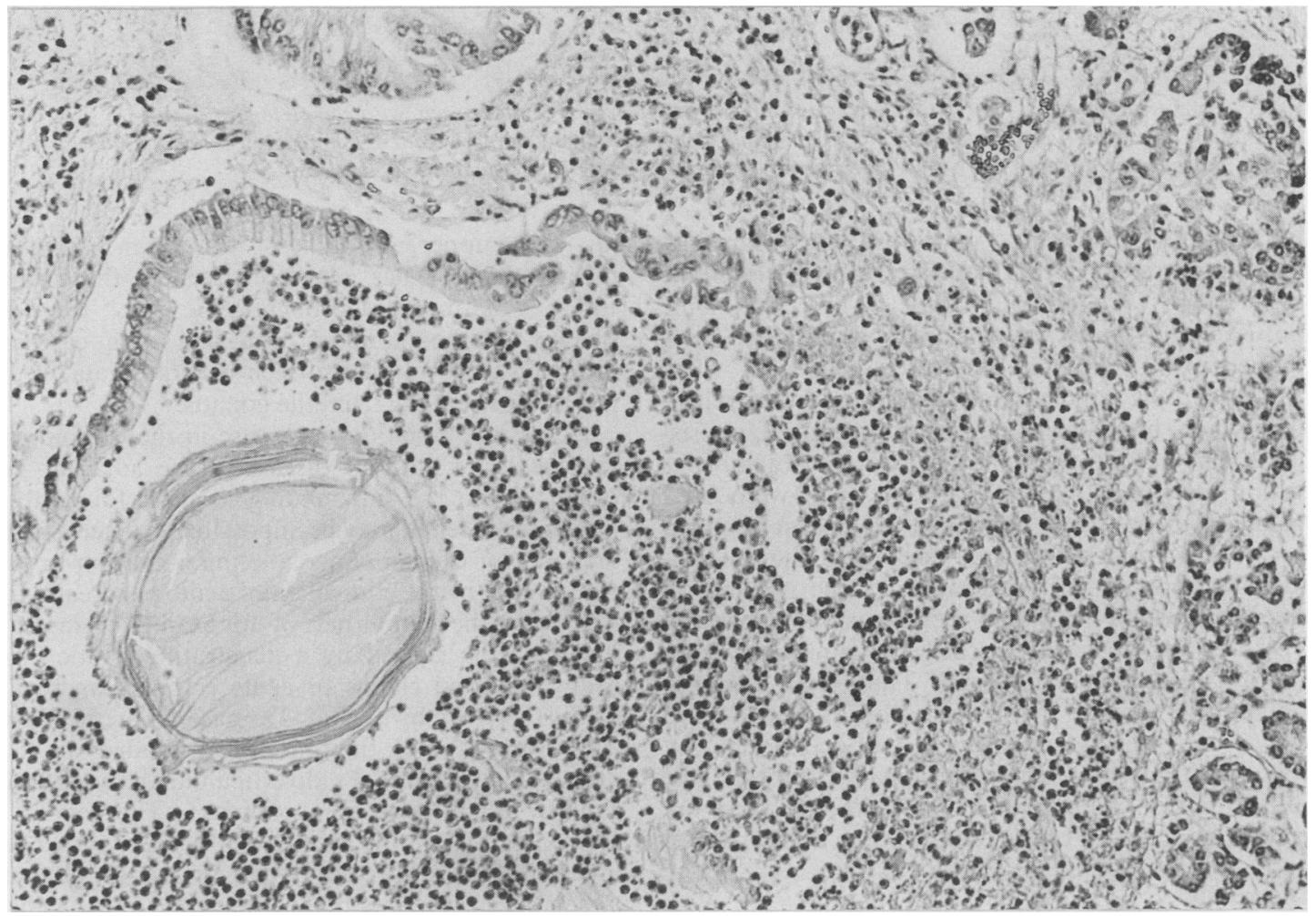

Fig 2 Duct within ectopic pancreas contains many neutrophil polymorphs, together with a laminated concretion. Duct epithelium is focally ulcerated and inflammatory exudate extends into immediately adjacent connective tissue stroma. (Haematoxylin and eosin.) 


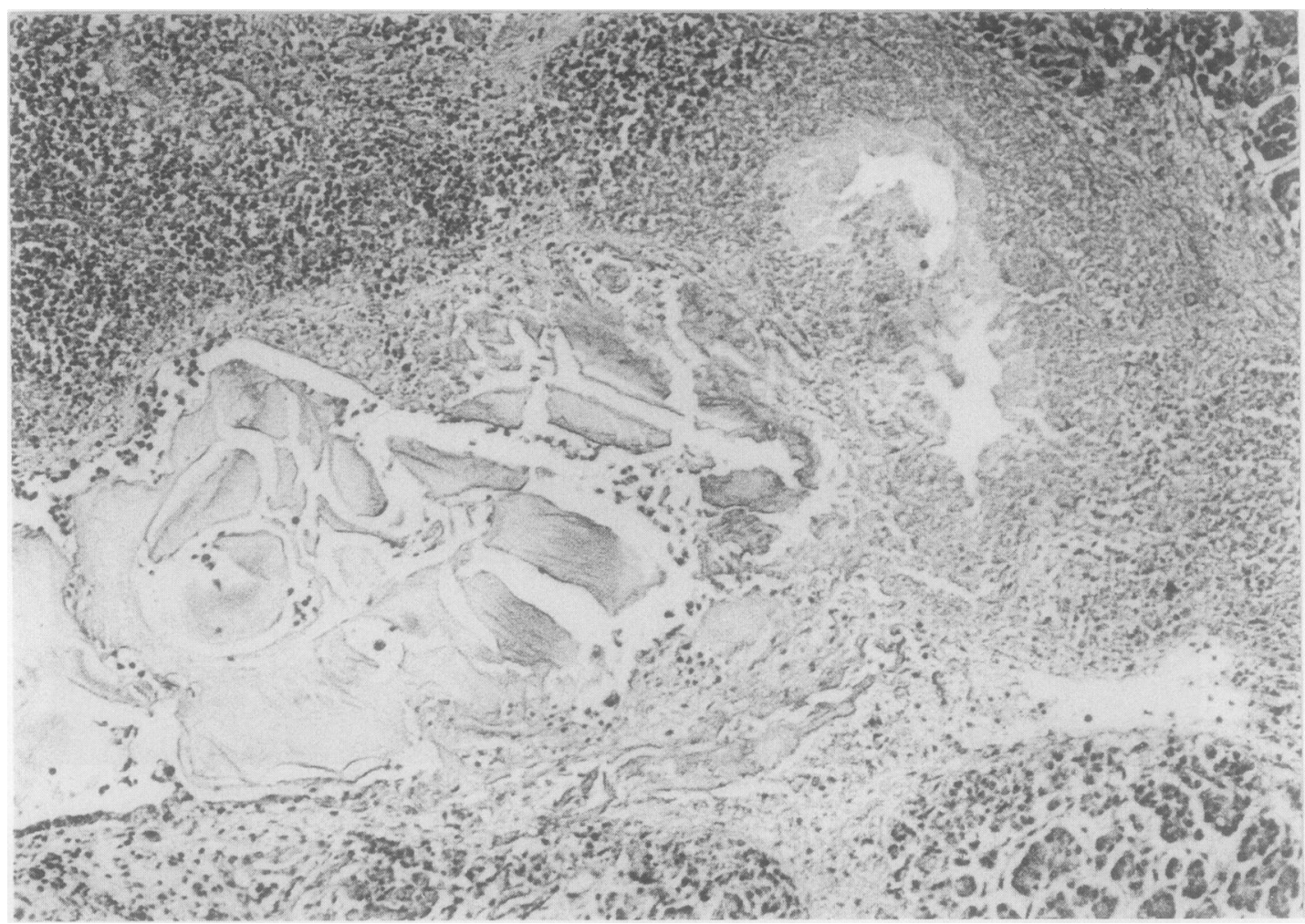

Fig 3 Duct within entopic pancreas, showing the most severe degree of damage seen, with complete destruction of epithelium. Lumen contains partly disrupted eosinophilic concretion, together with acute inflammatory exudate. Other areas in entopic pancreas are even more closely similar to appearances in fig 2. (Haematoxylin and eosin.)

inflammatory exudate, with extension through necrotic segments of the duct wall (fig 2). Eosinophilic concretions were obvious (fig 2). There was some diffuse infiltration of polymorphs into the connective tissue stroma, though no fat necrosis was seen.

The entopic pancreas contained many tiny yellow foci which, histological examination showed, consisted mainly of aggregates of neutrophil polymorphs within interlobular ducts. Affected ducts were filled with polymorphs and contained prominent rounded eosinophilic concretions; the duct walls showed segmental necrosis, with infiltration of the polymorph exudate through the wall in such areas of necrosis (fig 3). There was, however, very little inflammation within the adjacent pancreatic acini. There was a scanty polymorph exudate in the fat within the connective tissue septa near inflamed ducts, and occasional tiny foci of fat necrosis were seen. Apart from this, the inflammatory changes were similar to those in the ectopic pancreas in extent, distribution, and type.

\section{Discussion}

Ectopic pancreatic tissue may be found in various sites in the upper abdomen ${ }^{67}$ and in Meckel's diverticula. ${ }^{7-9}$ It has also been seen in the mediastinum, ${ }^{10}$ the lung, ${ }^{11}$ a bronchogenic cyst, ${ }^{12}$ the oesophagus, ${ }^{13}$ at the umbilicus ${ }^{14}$ and, in a recent case, in a fallopian tube. ${ }^{15}$ It is also seen in teratomata, ${ }^{16}{ }^{17}$ but not in those arising from the gonads. ${ }^{17}$

Acute inflammation may arise in the ectopic pancreas with or without disease in the adjacent host organ. When the surrounding tissue is found to be inflamed as well, it may be impossible to determine the sequence of events: pancreatic inflammation in such cases might be the equivalent of acute pancreatitis, or it might be the counterpart of-for example, pancreatic inflammation caused by a penetrating peptic ulcer. Many reported claims of acute ectopic pancreatitis might therefore be invalid. The case report by Taylor and Owen ${ }^{9}$ is valid; they carefully excluded any local disease in the Meckel's diverticulum that contained acutely inflamed ectopic pancreas. The report by Qizilbash, ${ }^{18}$ however, is of doubtful validity because inflammation was present both in the ectopic pancreas and in the gall bladder that contained it, and may have started in the gall bladder, rather than the ectopic 
pancreas. Similarly, a claim that acute ectopic pancreatitis led to gastric ulceration ${ }^{19}$ may also have reversed the true sequence of events. Reviews of reports on ectopic pancreas indicate that acute inflammation, thought to be equivalent to acute pancreatitis, is fairly common, ${ }^{720}$ though evidence for this claim is scanty and often based on a report which itself gives too little detail for adequate evaluation. ${ }^{21}$ In the case described in this report, inflammation in the ectopic pancreas was clearly centred on the duct system, and there was no ulceration of the adjacent jejunal mucosa or inflammation of the bowel wall or serosa.

In the United Kingdom cholelithiasis is the commonest disease associated with symptomatic acute pancreatitis. ${ }^{22}$ It is believed that inflammation is induced by pancreatic duct hypertension, which is caused by the passage of a gall stone down the common bile duct, particularly if the stone is of similar diameter to that of the lumen of the duct. ${ }^{23}$ Alcohol abuse is also a common cause of this type of inflammation, especially if detoxifying enzyme systems have been induced by long term abuse.

Accidental hypothermia is a relatively common cause of death, particularly in those aged 75 years and older, both in the United States ${ }^{24} 25$ and in the United $\mathrm{Kingdom}^{26}$; indeed, the incidence may be substantially underestimated in those dying outside hospital. ${ }^{27} \mathrm{~A}$ high proportion of such patients are found to have acute pancreatitis at necropsy, with disease ranging from minor local inflammation to lesions which would alone be sufficient to cause death. ${ }^{28-30}$ Similar findings were obtained when generalised hypothermia was used in a futile attempt to treat disseminated tumours, ${ }^{31}{ }^{32}$ and acute pancreatitis may also complicate cardiopulmonary bypass. ${ }^{33}$

The pathogenesis of inflammation in hypothermia is usually attributed to ischaemia following sludging in the sluggish blood stream ${ }^{22}$ and may therefore have a common pathway with the various other causes of so called "vascular" pancreatitis. ${ }^{34}$ Foulis performed a critical analysis of this association and suggested that the pathogenic mechanisms were not so simple. ${ }^{35} \mathrm{He}$ correlated his findings with those of his own earlier study ${ }^{3}$ and suggested that only a perilobular pattern of pancreatitis was secondary to hypothermia. Where the inflammation is periductal, he suggested that the pancreatitis and the hypothermia were secondary to a third factor, such as gallstones or alcohol abuse. These findings help unravel the pathogenesis of the case described in this report, though the poor clinical history is limiting.

The pancreatitis in this case was almost entirely limited to the ducts, and so hypothermia was not its cause. Even if the patient had passed a solitary and undetected gall stone, then inflammation would have been limited to the entopic pancreas, and so cholelith- iasis could not be a factor. The patient might have been an undetected alcohol abuser, though there were no hepatic stigmata of alcohol abuse. The possible role of uraemia is less easily assessed, though a recent reviewer of the pathogenesis of acute pancreatitis found o convincing evidence of any association. ${ }^{22}$ This leaves one major possibility: methyldopa.

Braganza puts forward an attractive hypothesis that suggests that the pancreas is a casualty of the hepatic detoxification of the various xenobiotics ingested with food or as therapeutic agents. ${ }^{36}$ Such compounds may be converted to toxic intermediates by superoxide anions generated by the cytochrome $\mathbf{P 4 5 0}$ system of hepatocytes, and these intermediates may be excreted into the bile. They may then damage the pancreas if this "toxic bile" refluxes into the pancreatic duct. The entopic pancreatitis may be explained in this way, for it is known that hepatocytes may oxidise methyldopa to toxic forms ${ }^{37}$ : acute pancreatitis is a rare but well established complication of treatment with methyldopa. ${ }^{38-40}$

In its original form Braganza's hypothesis ${ }^{36}$ still leaves the ectopic pancreatitis unexplained. She has, however, made a more recent suggestion which overcomes even this difficulty: the cytochrome P450 system of the pancreatic tissue itself may become induced to produce sufficient toxic intermediates to cause pancreatitis. ${ }^{2}$ Indeed, the difficulty of providing any other explanation of this case provides strong support for the validity of this hypothesis.

I am grateful to Dr Donald Longson for permission to report the clinical details of this case, to Dr David J F Dodwell for help with translations and to Margaret Banton for printing the photomicrographs.

\section{References}

1 Williams G. Acute pancreatic necrosis as a cause of sudden death. Br Med J 1954;i:1184-5.

2 Braganza JM. The pancreas. In: Pounder RE, ed. Recent advances in gastroenterology 6. Edinburgh: Churchill Livingstone, 1986:251-80.

3 Foulis AK. Histological evidence of initiating factors in acute necrotising pancreatitis in man. J Clin Pathol 1980;33:1125-31.

4 Foulis AK. Acute pancreatitis. In: Anthony PP, MacSween RNM, eds. Recent advances in histopathology 12. Edinburgh: Churchill Livingstone, 1984:188-96.

5 Cruikshank AH. Pathology of the pancreas. Berlin: SpringerVerlag, 1986:195-232.

6 Dolan RV, ReMine WH, Dockerty MB. The fate of pancreatic heterotopic tissue. Arch Surg 1974;109:762-5.

7 Lai ECS, Tomkins RK. Heterotopic pancreas. Review of a 26 year experience. Am J Surg 1986;151:697-700.

8 Artigas V, Calabuig R, Badia F, Ruis X, Allende L, Jover J. Meckel's diverticulum: value of ectopic tissue. Am J Surg 1986;151:631-4.

9 Taylor RH, Owen DA. Acute inflammation of pancreatic tissue in a Meckel's diverticulum. Can J Surg 1982;25:656-7. 
10 Tilson MD, Touloukian RJ. Mediastinal enteric sequestration with aberrant pancreas: a formes frustes of the intralobar sequestration. Arch Surg 1972;176:669-71.

11 Corrin B, Danel C, Allaway A, Warner JO, Lenney W. Intralobar pulmonary sequestration of ectopic pancreatic tissue with gastropancreatic duplication. Thorax 1985;40:637-8.

12 Jaschke W, Aleksic M, Aleksic D. Heterotopic pancreatic tissue in a bronchogenic cyst-diagnosis and therapy. Thorac Cardiovasc Surg 1982;30:58-60.

13 Razi MD. Ectopic pancreatic tissue of esophagus with massive upper gastrointestinal bleeding. Arch Surg 1966;92:101-4.

14 Caberwal D, Kogan SJ, Levitt SB. Ectopic pancreas presenting as an umbilical mass. J Pediatr Surg 1977;12:593-5.

15 Mason TE, Quagliarello JR. Ectopic pancreas in the fallopian tube: report of a first case. Obstet Gynecol 1976;48:705-35.

16 Crosby EH, Graham A. Mediastinal dermoid cyst. Report of a case in which there was pancreatic tissue, simulating intrathoracic goitre. JAMA 1932;98:1789-91.

17 Suda K, Mizuguchi K, Hebisawa A, Wakabayashi T, Saito S. Pancreatic tissue in teratoma. Arch Pathol Lab Med 1984; 108:835-7.

18 Qizilbash AH. Acute pancreatitis occurring in heterotopic pancreatic tissue in the gallbladder. Can J Surg 1976;19:413-4.

19 Chapman BM, Vogel WF, Schomaker TP. Massive gastric haemorrhage associated with aberrant pancreas in the stomach. Gastroenterology 1947;8:367-74.

20 Pearson S. Aberrant pancreas: review of the literature and report of 3 cases, one of which produced common and pancreatic duct obstruction. Arch Surg 1957;63:168-84.

21 de Castro Barbosa JJ, Dockerty MB, Waugh JM. Pancreatic heterotopia: review of the literature and report of 41 authenticated surgical cases, of which 25 were clinically significant. Surg Gynecol Obstet 1946;82:527-42.

22 Durr GH-K. Acute pancreatitis. In: HT Howat, H Sarles, eds. The exocrine pancreas. London: WB Saunders, 1979: 352-401.

23 Taylor TV, Armstrong CP. Migration of gall stones. $\mathrm{Br} \mathrm{Med} \mathrm{J}$ 1987;294:1320-2.

24 Rango N. Exposure-related hypothermia in the United States, 1970-79. Am J Public Health 1984;74:1159-60.

25 Centers for Disease Control. Hypothermia-associated deathsUnited States, 1968-1980. JAMA 1986;255:307-11.
26 Anonymous. Deaths in winter [Editorial]. Lancet 1985;ii:987-8.

27 Randall PE, Heath DF, Little RA. How common is accidental hypothermia? Arch Emerg Med 1985;2:174-5.

28 Duguid H, Simpson RG, Stowers JM. Accidental hypothermia. Lancet 1961;ii:1213-9.

29 Mant AK. Autopsy diagnosis of accidental hypothermia. $J$ Forensic Med 1969;16:126-9.

30 Moss J. Accidental severe hypothermia. Surg Gynecol Obstet 1986;162:501-13.

31 Sano ME, Smith LW. Fifty postmortem patients with cancer subjected to local or generalised refrigeration compared to a similar control group of 37 non-refrigerated patients. J Lab Clin Med 1940;26:443-56.

32 Smith LW. Pathologic changes observed in human tissues subjected to subcritical temperatures. Archives of Pathology 1940;30:424-38.

33 Haas GS, Warshaw AL, Daggett WM, Aretz HT. Acute pancreatitis after cardiopulmonary bypass. Am J Surg 1985;149:508-15.

34 Dreiling DA, Koller M, Su C-H. Vascular pancreatitis: a neglected disorder. Mount Sinai J Med 1986;53:482-4.

35 Foulis AK. Morphological study of the relation between accidental hypothermia and acute pancreatitis. J Clin Pathol 1982;35:1244-8.

36 Braganza JM. Pancreatic disease: a casualty of hepatic "detoxification"? Lancet 1983;ii:1000-3.

37 Dybing E, Nelson SD, Mitchell JR, Saame HA, Gillette JR. Oxidation of $\alpha$-methyldopa and other catechols by cytochrome P-450-generated superoxide anion: possible mechanism of methyldopa hepatitis. Mol Pharmacol 1976;12:911-20.

38 Rominger JM, Gutierrez JG, Curtis D, Chey WY. Methyldopainduced pancreatitis. Am J Dig Dis 1978;23:756-8.

39 Warren SE, Mitas J, Swerdlin AHR. Pancreatitis due to methyldopa: case report. Milit Med 1980;145:399-400.

40 van der Heide $\mathrm{H}$, ten Haaft MA, Stricker BHC. Pancreatitis caused by methyldopa. $\mathrm{Br} \mathrm{Med} J$ 1981;282:1930-1.

Requests for reprints to Dr E W Benbow, Department of Pathology, Stopford Building, University of Manchester, Oxford Road, Manchester M13 9PT, England. 